\title{
HUBUNGAN ANTARA ISAPAN BAYI DENGAN PRODUKSI ASI PADA IBU MENYUSUI DI RUMAH SAKIT ISLAM JEMURSARI SURABAYA
}

\author{
Tri Aprillia Tauriska, Farida Umamah
}

\author{
Universitas Nahdlatul Ulama Surabaya - J1 Smea 57 Surabaya \\ Email : umamahfarida@yahoo.com
}

\begin{abstract}
The correlation between baby's suck and breast milk production in breastfeeding mothers in RSI Jemursari Surabaya. The mothers feel reluctant to breastfeed their babies even though the exclusive breastfeeding has become a government's propaganda. The pre-data taken from 15 breastfeeding mothers inform that $60 \%$ had a low breast milk production. Purpose of this study was to find out the correlation between baby's suck and breast milk production in breastfeeding mothers in RSI Jemursari Surabaya.The design of study was analytic-observational done by applying cross sectional approach. The population involved all breastfeeding mothers as imumnunization visiting the hospital with their babies, totally 18 people, in which 17 respondents were taken by using probability sampling technique. The instrument used for collecting the data was a checklist. The variables used in this study were baby's suck and breast milk production. The data were analyzed by using Chi-Square test with the significance level $\alpha=0.05$.The result of study showed that nearly all of the babies (94.1\%) sucked correctly, whereas nearly all of the mothers (88.2\%) had sufficient breast milk production. Moreover, the result of statistic test showed that $p=0.018$ with the significance level $\alpha=0.05$ so that $p<\alpha$. It also meant that $H_{0}$ was rejected. The conclusion of study often the babies suck correctly, breast milk is produced. Hence, the breastfeeding mothers to still maintaining for breastfeed their baby with train them how to breastfeed correctly to increase breast milk production.
\end{abstract}

Abstrak : Hubungan Antara Isapan Bayi Dengan Produksi Asi Pada Ibu Menyusui Di Rsi Jemursari Surabaya. Masih ada ibu enggan menyusui bayinya walaupun sudah digalakkan ASI eksklusif. Data awal diperoleh dari 15 ibu menyusui di RSI Jemursari Surabaya 60\% mengatakan produksi ASI-nya kurang. Tujuan penelitian ini untuk mengetahui hubungan antara isapan bayi dengan produksi ASI pada ibu menyusui di RSI Jemursari Surabaya.Desain yang digunakan analitik observasional dengan pendekatan cross sectional. Populasi semua ibu menyusui yang datang bersama bayinya saat kunjungan imunisasi di RSI Jemursari Surabaya 18 orang dan didapatkan sampel 17 orang. Teknik yang digunakan probability sampling. Instrumen penelitian menggunakan checklist. Variabel yang digunakan isapan bayi dan produksi ASI. Dianalis menggunakan uji Chi Square tidak memenuhi syarat sehingga dilanjutkan Uji Eksak Fisher dengan tingkat kemaknaan( $\alpha=0,05)$.Hasil penelitian menunjukkan hampir seluruhnya $(94,1 \%)$ isapan bayi benar dan hampir seluruhnya $(88,2 \%)$ mempunyai produksi ASI cukup. Hasil uji statistik didapatkan bahwa $\rho=0,018$ dengan tingkat signifikan $\alpha=0,05$ berarti $\rho<\alpha$ maka $\mathrm{H}_{0}$ ditolak. Simpulan dari penelitian semakin sering bayi mengisap payudara dengan benar, ASI semakin sering diproduksi. Diharapkan bagi ibu menyusui tetap mempertahankan untuk menyusui bayinya dengan cara menyusui yang benar untuk meningkatkan produksi ASI.

Kata Kunci : Isapan Bayi, Produksi ASI 


\section{PENDAHULUAN}

Salah satu tujuan pembangunan nasional adalah membangun sumber daya manusia yang berkualitas agar mereka dapat melanjutkan perjuangan pembangunan nasional. Sumber daya manusia yang berkualitas tentunya harus dibentuk sejak awal. Pemberian ASI dan proses menyusui yang benar merupakan sarana yang dapat diandalkan untuk membangun sumber daya manusia. Namun saat ini masih banyak ibu yang mengalami kesulitan untuk menyusui bayinya, disebabkan kemampuan bayi untuk menghisap ASI kurang sempurna sehingga secara keseluruhan proses menyusu terganggu. Kemampuan bayi untuk menghisap ASI kurang sempurna disebabkan terganggunya proses alami bayi untuk menyusu sejak dilahirkan, biasanya penolong persalinan selalu memisahkan bayi dari ibunya segera setelah lahir untuk dibersihkan, ditimbang dan diberi pakaian sehingga menyebabkan produksi ASI akan berkurang (Shillatuddiniyah, 2013). Dampak yang terjadi jika ibu tidak menyusui bayinya yaitu terputusnya hubungan batin antara sang ibu dan sang anak, rasa sakit pada payudara yang membengkak saat diperah atau saat digunakan pompa atau mesin pompa ASI, let down milk reflex ASI tidak kunjung tiba, ketidak-seimbangan antara produksi ASI/hari (Sitepoe, 2013).

Pemberian ASI di Indonesia masih tergolong rendah. Berdasarkan riskesdas 2010, angka pemberian ASI eksklusif bagi bayi yang berusia dibawah 6 bulan adalah sebesar 15,3\%. Bayi yang menggunakan susu formula mencapai 27,9\%. Pemberian ASI eksklusif di 51 negara berdasarkan pengukuran indikator yang telah ditetapkan, Indonesia rangking ke 37 dari 51 negara (AIMI, 2013).

Data awal yang di peroleh di RSI Jemursari dengan mewawancarai $15 \mathrm{ibu}$ yang menyusui pada bulan Maret 2014. Menunjukkan ibu yang menyusui bayinya terdapat 6 orang $(40 \%)$ dan ibu yang tidak menyusui bayinya terdapat 9 orang $(60 \%)$.
Ibu yang tidak menyusui bayinya memiliki alasan yaitu mengatakan produksi ASI-nya kurang.

Faktor yang mempengaruhi produksi ASI yaitu : makanan, apabila konsumsi makanan ibu secara teratur dan cukup mengandung gizi yang diperlukan akan meningkatkan produksi ASI. Ketenangan jiwa dan pikiran, ibu yang selalu dalam keadaan ketegangan emosional akan menurunkan volume ASI bahkan tidak akan terjadi produksi ASI. Anatomis buah dada, bila jumlah lobus dan lobulus dalam buah dada berkurang, dengan demikian produksi ASI berkurang. Fisiologi, terbentuknya ASI dipengaruhi hormon prolaktin yang menentukan dalam hal pengadaan dan mempertahankan sekresi air susu. Isapan anak, isapan bayi yang efektif akan mengoptimalkan rangsangan ke otak yang akan memerintahkan untuk memproduksi hormon prolaktin dan oksitosin. Faktor obat, obat yang mengandung hormon akan mempengaruhi hormon prolaktin dan oksitosin, akan mempengaruhi pembentukan dan pengeluaran ASI. Bagi ibu yang dalam masa menyusui tidak dianjurkan menggunakan kontrasepsi pil yang mengandung hormon estrogen, karena hal ini dapat mengurangi jumlah produksi ASI (Kristiyanasari, 2009).

Upaya yang dapat diterapkan oleh bidan untuk mendukung menyusui yaitu mempunyai kebijakan tertulis tentang menyusui, melatih semua staf pelayanan kesehatan dengan keterampilan untuk menerapkan kebijakan tersebut, menjelaskan kepada ibu hamil tentang manfaat dan manajemen laktasi, membantu ibu-ibu mulai menyusui bayinya dalam 30 menit setelah melahirkan, memperlihatkan kepada ibu bagaimana cara menyusui dan mempertahankannya, tidak memberikan makan atau minuman apapun selain ASI kepada bayi baru lahir, melaksanakan rawat gabung, mendukung pemberian ASI tanpa jadwal, tidak memberikan dot atau kempeng, membentuk dan membantu 
pengembangan kelompok pendukung ibu menyusui (Yuli Astutik, 2014).

\section{METODE}

Desain penelitian yang digunakan adalah analitik dengan pendekatan yang digunakan adalah cross sectional, yaitu suatu penelitian dimana variabel independen (isapan bayi) dan dependen (produksi ASI) diobservasi hanya sekali saja. Populasi dalam penelitian ini adalah semua ibu menyusui yang datang bersama bayinya saat kunjungan imunisasi di RSI Jemursari Surabaya sebesar 18 orang.Sampel adalah sebagian ibu menyusui di RSI Jemursari Surabaya. Tehnik sampling dilakukan secara probability sampling dengan teknik simple random sampling dimana semua subyek mempunyai kesempatan yang sama untuk dijadikan sampel dengan cara acak. Variabel independent adalah ispan bayi dan variabel dependent adalah produksi ASI.

Data dianalisis dengan menggunakan uji statistik Chi Square tidak memenuhi syarat sehingga dilanjutkan menggunakan Uji Fisher Exact dengan tingkat kemaknaan $\alpha=0,05 . \mathrm{H}_{0}$ ditolak jika $\rho<\alpha$, asumsi ada hubungan antara isapan bayi dengan produksi ASI.

\section{HASIL PENELITIAN}

Karakteristik Responden Berdasarkan Isapan Bayi

Tabel 1 : Distribusi Frekuensi Isapan Bayi Pada Ibu Menyusui di RSI Jemursari Surabaya Pada Bulan Juni 2014.

\begin{tabular}{|c|c|c|}
\hline Isapan bayi & Frekuensi & $\%$ \\
\hline Isapan benar & 16 & 94,1 \\
\hline Isapan tidak benar & 1 & 5,9 \\
\hline Jumlah & 17 & 100 \\
\hline
\end{tabular}

Berdasarkan tabel 1 dapat diketahui dari 17 responden hampir seluruhnya $(94.1 \%)$ isapan bayi benar

Tabel 2 Distribusi Frekuensi Produksi ASI Pada Ibu Menyusui di RSI Jemursari Surabaya Pada Bulan Juni 2014.

\begin{tabular}{|c|c|l|}
\hline Produksi ASI & Frekuensi & $\%$ \\
\hline Produksi ASI cukup & 15 & 88,2 \\
\hline Produksi ASI kurang & 2 & 11,8 \\
\hline Jumlah & 17 & 100 \\
\hline
\end{tabular}

Pada tabel 2 dapat diketahui dari 17 responden hampir seluruhnya (88.2\%) produksi ASI cukup.

Tabel3. Hasil Uji Analisis Isapan Bayi Dengan Produksi ASI Pada Ibu Menyusui di RSI Jemursari Surabaya Pada Bulan Juni 2014.

\begin{tabular}{|c|c|c|c|c|c|c|c|}
\hline \multirow{2}{*}{$\begin{array}{c}\text { Isapa } \\
\text { n } \\
\text { Bayi }\end{array}$} & \multicolumn{7}{|c|}{ Produksi ASI } \\
\hline & \multicolumn{2}{|c|}{ Cukup } & \multicolumn{2}{|c|}{ Kurang } & \multicolumn{2}{|c|}{ Total } & $\rho$ valu \\
\hline Benar & 15 & 94 & 1 & 4 & 16 & 100 & \multirow{3}{*}{0,018} \\
\hline $\begin{array}{l}\text { Tidak } \\
\text { benar }\end{array}$ & 0 & 0 & 1 & 100 & 1 & 100 & \\
\hline Total & 15 & 88 & 2 & 12 & & 100 & \\
\hline
\end{tabular}

Berdasar tabel 3 menunjukkan hasil analisis hubungan isapan bayi dan produksi ASI diperoleh dari 16 responden isapan bayi benar hampir seluruhnya (94\%) mempunyai produksi ASI cukup. Dan dari 1 responden yang isapan bayi tidak benar seluruhnya $(100 \%)$ produksi ASI kurang. Hasil uji menggunakan uji Chi Square tidak memenuhi syarat sehingga dilanjutkan menggunakan Uji Fisher Exact dengan menggunakan SPSS for windows 16,0 didapatkan hasil $\rho=0,018<\alpha=0,05$ maka $\mathrm{H}_{0}$ ditolak artinya ada hubungan antara isapan bayi dengan produksi ASI. 


\section{PEMBAHASAN}

1. Isapan Bayi

Tabel 5.5 menunjukkan bahwa dari 17 responden hampir seluruhnya (94.1\%), isapan bayi benar. Hal ini disebabkan hampir seluruhnya ibu menyusui bayinya dengan tepat pada saat menyusui, seperti cara menempatkan posisi mulut pada payudara, sehingga isapan bayi seluruhnya benar. Jika isapan bayi benar maka akan menstimulasi hipotalamus yang akan merangsang kelenjar hipofise anterior menghasilkan hormon prolaktin dan hipofise posterior menghasilkan hormon oksitosin. Isapan bayi benar adalah : Mulut bayi terbuka lebar, bayi tampak menghisap kuat, puting susu ibu tidak terasa nyeri (Soetjiningsih, 2004). Pipi membulat, lebih banyak areola diatas mulut, menghisap pelan, dalam dan diselingi istirahat, dapat mendengar suara saat bayi menelan (Agustina, 2012). Ibu tidak memegang atau menyangga payudara, lidah bayi berada dibawah puting susu, terlihat gerakan sendi rahang bayi yang aktif dalam menyusu (Suherni, 2009). Faktor yang mempengaruhi isapan bayi adalah bayi berat lahir rendah, bayi dengan lidah pendek dan masa gestasi saat melahirkan (Kristiyanasari, 2009).

Tabel 5.1 dapat diketahui dari 17 responden hampir seluruhnya $(82,4 \%)$ memiliki bentuk puting susu menonjol. Keberhasilan proses laktasi adalah salah satunya bentuk puting susu. Bentuk puting susu yang menonjol akan memudahkan bayi saat menyusu, sehingga bayi tidak mengalami kesulitan mengisap, sedangkan pada puting susu yang tenggelam bayi mengalami kesulitan mengisap ASI, maka bayi akan haus dan rewel lalu menangis karena bayi tidak bisa mengisap dengan optimal. Hal ini dipertegas oleh Nasution (2005) Perawatan payudara perlu dilakukan selama kehamilan sampai masa menyusui agar puting susu menonjol, melenturkan puting susu, dan menjaga kebersihan sehingga memudahkan bayi saat mengisap.

Tabel 5.2 dapat diketahui dari 17 responden seluruhnya (100\%) memiliki bayi dengan berat lahir normal > 2500 gram. Berat badan lahir normal > 2500 gram adalah berat badan yang struktur organnya sudah matur. Reflek dalam mekanisme isapan bayi sudah baik. Kemampuan isapan dan menelan juga baik, sehingga saat ibu menyusui bayi dapat menghisap dengan tepat. Bayi dengan berat lahir normal mempunyai reflek mengisap dan menelan yang sudah baik. Bayi berat lahir rendah mempunyai masalah menyusui karena refleks menghisapnya masih relatif lemah yang akan mempengaruhi stimulasi hormon prolaktin dan oksitosin dalam memproduksi ASI (Kristiyanasari, 2009).

Tabel 5.4 dapat diketahui dari 17 responden hampir seluruhnya $(88.2 \%)$ memiliki masa gestasi $>34$ minggu. Bayi lahir diatas >34 minggu adalah bayi yang sudah mampu hidup diluar kandungan karena mempunyai organ-organ yang sudah baik. Sehingga kemampuan menghisap lebih efektif. Sedangkan bayi dengan <34 minggu tidak mempunyai kemampuan menghisap secara efektif dan lemah. Bayi lahir pada masa gestasi $>34$ minggu dapat mempengaruhi isapan bayi. Hal ini disebabkan bayi yang lahir prematur (masa gestasi kurang dari 34 minggu) sangat lemah dan tidak mampu menghisap secara efektif (Yanti dkk, 2011).

\section{Produksi ASI}

Tabel 5.6 menjelaskan bahwa dari 17 hampir seluruhnya (88.2\%) produksi ASInya cukup. Hal ini disebabkan produksi ASI cukup sangat berperan dalam proses laktasi. Dengan produksi ASI yang cukup maka kebutuhan bayi akan terpenuhi. Tanda bahwa produksiASI cukup yaitu sebelum disusui payudara ibu terasa tegang, ASI dapat keluar dari puting dengan sendirinya, setelah menyusu maka bayi akan tertidur atau tenang selama 1-2 
jam (Yuli Astutik, 2014). Memerah ASI dengan tangan atau pompa ASI (Chumbley, 2004).

Tabel 5.3 dapat diketahui dari 17 responden sebagian besar $(58,8 \%)$ tidak bekerja. Ibu yang tidak bekerja mempunyai waktu yang banyak untuk beristirahat, sehingga ibu tidak terlalu capek dan akan mempengaruhi pada pengeluaran hormon oksitosin dan prolaktin sehingga mempengaruhi produksi ASI. Faktor yang turut mempengaruhi pengeluaran dan produksi ASI adalah pola istirahat. Apabila kondisi ibu capek dan kurang istirahat maka ASI pun akan berkurang (Riksani, 2011).

3. Hubungan Antara Isapan Bayi dengan Produksi ASI pada Ibu Menyusui

Hasil uji menggunakan uji Chi Square tidak memenuhi syarat sehingga dilanjutkan menggunakan Uji Fisher Exact dengan menggunakan SPSS for windows 16,0 didapatkan hasil $\rho=0,018<\alpha=0,05$ maka $\mathrm{H}_{0}$ ditolak artinya ada hubungan antara isapan bayi dengan produksi ASI di RSI Jemursari Surabaya.

Tabel 5.7 menunjukkan hasil analisis hubungan isapan bayi dan produksi ASI diperoleh 16 responden isapan bayi benar hampir seluruhnya (94\%) mempunyai produksi ASI cukup dan yang mempunyai produksi ASI kurang hanya (6\%). Gerakan Isapan anak dapat mempengaruhi stimulus pada puting susu. Dalam puting susu terdapat banyak ujung saraf sensoris. Bila dirangsang, timbul implus menuju hipotalamus selanjutnya ke kelenjar hipofise anterior (bagian depan) sehingga kelenjar ini menghasilkan hormon prolaktin. Rangsangan puting susu tidak hanya diteruskan sampai ke kelenjar hipofise anterior, tetapi juga ke kelenjar hipofise posterior (bagian belakang), yang menghasilkan hormon oksitosin. Salah satu usaha untuk memperbanyak ASI adalah dengan menyusui anak secara teratur. Semakin sering anak menghisap puting susu ibu, maka akan terjadi peningkatan produksi ASI. Dan sebaliknya jika anak berhenti menyusu maka terjadi penurunan ASI.

Saat bayi mulai menghisap ASI, akan terjadi dua reflek yang akan menyebabkan ASI keluar pada saat yang tepat pula, yaitu reflek pembentukan /produksi ASI atau reflek prolaktin yang dirangsang oleh hormon prolaktin dan refleks pengaliran/pelepasan ASI (let down reflex). Bila bayi mengisap puting payudara, maka akan diproduksi suatu hormon yang disebut prolaktin, yang mengatur sel dalam alveoli agar memproduksi air susu. Air susu tersebut dikumpulkan ke dalam saluran air susu. Kedua, reflek mengeluarkan (let down reflex). Isapan bayi juga akan merangsang produksi hormon lain yaitu oksitosin, yang membuat sel otot disekitar alveoli berkontraksi, sehingga air susu didorong menuju puting payudara. Jadi semakin bayi mengisap, maka semakin banyak air susu yang dihasilkan (Perinasia, 2008).

Faktor lain yang mempengaruhi produksi ASI yaitu status pekerjaan. Ibu yang tidak bekerja mempunyai waktu yang banyak untuk beristirahat, sehingga ibu tidak terlalu capek dan akan mempengaruhi pada pengeluaran hormon oksitosin dan prolaktin sehingga mempengaruhi produksi ASI. Apabila kondisi ibu capek dan kurang istirahat maka ASI pun akan berkurang (Riksani, 2011).

\section{SIMPULAN}

1. Ibu menyusui di RSI Jemursari Surabaya hampir seluruhnya bayinya mengisap dengan benar.

2. Ibu menyusui di RSI Jemursari Surabaya hampir seluruhnya produksi ASI cukup.

3. Ada hubungan antara isapan bayi dengan produksi ASI pada ibu menyusui di RSI Jemursari Surabaya. 
DAFTAR PUSTAKA

AIMI (2013). Memberikaan Bayi Anda ASI. http//aimi-asi.org/pernyataanasosiasi-menyusui-indonesia. Diakses tanggal 14 April 2014

Agustina, F. (2012). Bayi Cukup ASI. http//repository.usu.ac.id. Artikel diakses tanggal 16 Mei 2014

Arikunto, Suharsimi. (2006). Prosedur Penelitian Suatu Pendekatan Praktek, Jakarta, Rineka Cipta

Bahiyatun, (2009). Buku Ajar Asuhan Kebidanan Nifas Normal. Jakarta, EGC

Chumbley, Jane. (2004). Menyusui. Jakarta, Erlangga

Hidayat, A. Aziz Alimul. (2007). Metode Penelitian Kebidanan dan Teknik Analisis Data. Jakarta, Salemba Medika

Jane, M., Jane, B., Karen, H. (2006). Menyusui. Jakarta, Arcan

Jannah, Nurul (2011). Asuhan Kebidanan Ibu Nifas. Jogjakarta, Ar-Ruzz

Khasanah, Nur (2012). ASI atau Susu Formula Ya?. Jogjakarta, FlashBooks

Kristiyanasari, Weni (2009). ASI, Menyusui dan Sadari. Yogyakarta, Nuha Medika

Majid (2004). Menyusui ASI Eksklusif. Jurnal. Sumatera Utara : Universitas Sumatera Utara

Notoadmojo, Soekidjo (2005). Metodologi Penelitian Kesehatan. Jakarta, Rineka Cipta
Novianti, Ratih (2009). Menyusui Itu Indah. Yogyakarta, Octopus

Nursalam (2011). Konsep dan Penerapan Metodologi Penelitian Ilmu Keperawatan Pedoman Penulisan Skripsi, Thesis dan Instrumen Penelitian Keperawata, Edisi kedua. Jakarta, Salemba Medika

Oktaviani (2012). ASI Eksklusif. Http//Oktaviani Sc.Blogspot. Diakses tanggal 14 April 2014

Perinasia (2008). Anatomi dan Fisiologi Laktasi. http://www.scribd.com. Diakses tanggal 19 April 2014

Ramaiah, Savitri. (2007). Manfaat ASI dan Menyusui. Jakarta, PT. Bhuana Ilmu Populer Kelompok Graha Medika

Riksani, Ria. (2011). Keajaiban ASI. Jakarta : Dunia Sehat

Shillatuddiniyah (2013). Hubungan inisiasi menyusui Dini dengan Kecepatan Keluarnya ASI Pada Postpartum Di BPS Firda Tuban tahun 2009. Skripsi dikutip dari http/l Shillatuddiniyah.blogspot. Diakses tanggal 26 Mei 2014

Sitepoe, Mangku. (2013). ASI Eksklusif. Jakarta, PT Indeks

Soetjiningsih (2004). ASI Pe tunjuk Untuk Tenaga Kesehatan. Jakarta, EGC

Suherni, Hesty,W., Anist, R.(2009). Perawatan Masa Nifas, Cetakan ke-IV. Yogyakarta, Penerbit Fitramaya

Yanti, D. Sundawati, D. (2011). Asuhan Kebidanan Masa Nifas. Bandung, PT Rafika Aditama 
Yuli Astutik, Reni. (2014). Payudara dan

Laktasi. Jakarta, Salemba Medika 